\title{
Cognitive Behavioral Therapy in a One-Session Treatment for a Preschooler With Specific Phobias
}

\author{
Helen Kershaw, MCP \\ Lara J. Farrell, PhD \\ Caroline Donovan, $\mathrm{PhD}$ \\ School of Applied Psychology and Menzies Health Institute Queensland, \\ Griffith University, Queensland, Australia \\ Thomas Ollendick, $\mathrm{PhD}$ \\ Child Study Centre, Virginia Polytechnic Institute and State University
}

\begin{abstract}
Anxiety disorders among preschool-aged children are as prevalent as in older children, yet younger children are even less likely to receive treatment for these frequently impairing childhood disorders (Egger \& Angold, 2006). Specific phobias (SPs) are often the earliest form of anxiety to onset, affect $2.3 \%$ of preschoolers (Egger \& Angold, 2006), and tend to be stable from 3 years of age to at least 6 years of age (Bufferd, Dougherty, Carlson, Rose, \& Klein, 2012). Recently, our group developed and piloted a modified intensive one-session treatment (OST) incorporating play therapy for preschoolers with SP (Farrell, Kershaw, \& Ollendick, in press). Given that highly fearful young children may find concentrated, rapid exposure therapy highly confronting, we integrated play therapy into the commencement of this treatment to (a) assist with rapid rapport building with the therapist and (b) enhance the child's motivation through engaging them with play. An initial, controlled, baseline case series $(N=4)$ provided preliminary evidence of the feasibility, acceptability, and effectiveness of this innovative onesession (3 hours) therapy-POP! Pre-schoolers Overcoming Phobias (POP; Farrell et al., in press). The approach combines child-centered, nondirective play therapy (during Hour 1) and empirically supported OST (during Hours 2 and 3), with 4-year-old preschool children with clinical SPs of dogs. This article presents a case description of POP, describing the assessment approach, cognitive-behavioral case formulation, and intensive treatment of a 4-year-old girl who presented with a severe SP of dogs, along with various other comorbid SPs.
\end{abstract}

Keywords: specific phobia; children; preschool; one-session treatment (OST); cognitive behavioral therapy (CBT); play therapy

hildhood anxiety disorders, including specific phobias (SPs), are among the most prevalent form of mental health disorders, affecting $14 \%-25 \%$ of community children at some point in their life (Costello, Egger, \& Angold, 2005). Although highly prevalent, debilitating, and persistent, less than one quarter of children actually receive treatment, and even fewer 
receive specialist, evidence-based treatments (Oh, Mathers, Hiscock, Wake, \& Bayer, 2015). Recent research has also found that anxiety disorders are as prevalent among preschoolers as older children, yet younger children are even less likely to receive treatment (Egger \& Angold, 2006). SPs are often the earliest form of anxiety to onset, affect $2.3 \%$ of preschoolers (Egger \& Angold, 2006), and tend to be stable across early development, with evidence that SP at 3 years predicts SP at 6 years of age (Bufferd et al., 2012). Moreover, SPs in childhood are predictive of a host of mental health problems later in life, including depression, other anxiety disorders, and substance abuse (Bittner et al., 2007; Cole, Peeke, Martin, Truglio, \& Seroczynski, 1998; Gregory et al., 2007; Kendall, Safford, Flannery-Schroeder, \& Webb, 2004). Thus, intervening early by treating early childhood SPs may provide an opportunity to improve the long-term emotional functioning of children and youth. Indeed, Rapee (2013) recently provided evidence that early intervention, targeting behaviorally inhibited preschool-aged children, led to significant reductions in internalizing disorders among adolescent girls, 11 years following intervention, relative to controls who did not receive the intervention.

Although typical childhood fears are normative and transient, childhood SPs by contrast are persistent, distressing for the child and family alike, and are frequently associated with significant impairments in functioning (American Psychiatric Association [APA], 2013). SPs take many forms but are grouped across five broad domains based on Diagnostic and Statistical Manual of Mental Disorders (5th ed.; DSM-5; APA, 2013) criteria including (a) fear of animals, (b) natural/ environment fears (e.g., storms, dark), (c) situational fears (e.g., lifts, heights), (d) blood-injection injury fears, and (e) other fears (e.g., costume characters). For most youngsters with SPs, they also tend to experience other comorbid anxiety disorders and frequently have more than one SP. For example, in our recent treatment trials for SPs in children aged 7 years and older, we found that more than $90 \%$ had a second comorbid diagnosis, and almost 50\% had at least three comorbid diagnoses (Farrell et al., in press; Ollendick et al., 2009).

Given the high prevalence and significant problematic consequences of preschool anxiety disorders, it is not surprising that there has been a recent surge of empirical interest into their treatment (Hirshfeld-Becker, Micco, Mazursky, Bruett, \& Henin, 2011). Research in this area provides preliminary support for cognitive behavioral therapy (CBT) in the treatment of preschool anxiety disorders, although the vast majority of studies to date have included samples of mixed separation anxiety disorder, generalized anxiety disorder, social phobia, and SPs (Donovan \& March, 2014; Hirshfeld-Becker et al., 2011; Waters, Ford, Wharton, \& Cobham, 2009). Trials have included CBT treatments delivered primarily to parents of anxious preschoolers (CartwrightHatton, Reynolds, \& Wilson, 2011; van der Sluis, van der Bruggen, Brechman-Toussaint, Thissen, \& Bögels, 2012), as well as child-focused and combined child and parent CBT, delivered either individually (Hirshfeld-Becker et al., 2010) or in group format (Waters et al., 2009), with the treatments approximately 10 sessions in length. Evidence also supports parent-focused group CBT for the prevention of anxiety disorders, by targeting young children at higher risk for developing anxiety (Fox \& Fine, 2012; Kennedy et al., 2009; Rapee, Kennedy, Ingram, Edwards, \& Sweeney, 2005). Although encouraging, the fact remains that fewer than 1 in 5 affected youth receive treatment for anxiety disorders (Merikangas et al., 2011). Families are busy entities, and difficulties associated with attending treatment for the 6-10 sessions required by most CBT programs for preschoolers are frequently deemed burdensome by parents (Freeman et al., 2008; Waters et al., 2009). Furthermore, treatment is often costly. Recently, Donovan and March (2014) delivered CBT online to parents to address some of these barriers and found evidence for positive outcomes following 10 sessions relative to a wait list. Although online treatments improve access and reduce burden on families, the majority remains lengthy in course. More time-limited models of treatment delivery may improve reach of evidence-based CBT programs, further reduce burden, and provide more rapid relief for the many young children suffering from early onset SPs. 
The one-session treatment (OST) approach developed by Öst (1989) and, later, Öst and Ollendick (2001) for children has been deemed well-established (Davis \& Ollendick, 2005) and provides an extremely time- and cost-efficient alternative to traditional longer term CBT approaches for child SPs. OST incorporates in vivo exposure, cognitive challenges, participant modeling, positive reinforcement, and psychoeducation in a single session maximized to 3 hours. Empirical support for OST has been demonstrated in 10 studies, including 3 large randomized controlled trials (RCTs; Ollendick et al., 2015; Ollendick et al., 2009; Öst, Svensson, Hellström, \& Lindwall, 2001) and 7 smaller clinical trials for a diverse range of SP subtypes in youth aged 7 years and older (Farrell et al., in press; Flatt \& King, 2010; Leutgeb, Schäfer, Köchel, \& Schienle, 2012; Leutgeb \& Schienle, 2012; Muris, Merchelback, \& Collaris, 1997; Waters et al., 2014). In these studies, OST has been found to be superior to wait-list control (Flatt \& King, 2010; Ollendick et al., 2009; Öst et al., 2001), psychological placebo (Ollendick et al., 2009), and eye movement desensitization and reprocessing therapy (Muris et al., 1997; Muris, Merckelbach, Holdrinet, \& Sijsenaar, 1998). In the largest RCT of OST to date, 196 children (aged younger than 7 years) across two countries (United States and Sweden) were randomized to OST, education support, or wait-list control, with outcomes demonstrating significant benefits for OST relative to both control conditions (Ollendick et al., 2009). More recently, Ollendick et al. (2015) examined the efficacy of a parent-augmented OST relative to standard OST and found that both treatments were equally effective. An examination of predictors of outcomes, however, found that younger children in the trial fared significantly less well to both treatment relative to older children. In a recently completed RCT of OST for children aged 7-14 years with SPs, we found that 78\% of our intent-to-treat (ITT) sample who received OST were free of their primary SP diagnosis, and furthermore, almost $50 \%$ of the ITT sample were free of all diagnoses (at pretreatment, the mean number of diagnoses was 3.5; Farrell et al., in press). These findings suggest that OST may be an excellent first-line treatment, given its efficiency and efficacy for not only SPs but also other comorbid anxiety and mood disorders. However, modifications to OST for younger children may be necessary to enhance outcomes. Ollendick and Muris (2015) in their seminal review suggest that OST may need to be modified as a function of development for younger children and suggest that play therapy approaches may be one such way to improve the efficacy of OST among younger children.

To date, there have been no controlled trials of OST for preschoolers with SP; however, there have been several case studies and uncontrolled trials of variants of play therapy and/ or behavioral therapy for childhood fears. For example, May, Rudy, Davis, and Matson (2013) describe a case study of two young children ( 4 and 5 years old) who received 10-13 sessions of behavioral therapy (including exposure, reinforced practice, and participant modelling). Both children achieved complete remission, and gains were maintained to 7-month follow-up. In a much larger controlled trial, Santacruz, Méndez, and Sánchez-Meca (2006) evaluated the effectiveness of two parent-led interventions for young children's darkness fears, which included exposure therapy and play: (a) bibliotherapy and games (BG) versus (b) emotive performances (EP) relative to (c) a no-treatment control (Santacruz et al., 2006). Parents were first trained in the interventions over five weekly sessions, and then BG and EP were delivered by the parents within the home environment. BG consisted of the parents reading a 12-chapter treatment story to the child, incorporating nine in-vivo or imaginal exposure games where the child exposed themselves to being in darkness. EP similarly consisted of games encouraging brief exposure tasks to the dark and the use of a token economy system to reward the child for completing exposure games. Seventy-eight community children were randomized to the three conditions, with both BG and $\mathrm{EP}$ associated with reductions in fear at 12 -month follow-up. However, given that parents were required to deliver the treatment at home, there was very high attrition across the study with almost $25 \%$ of parents not completing the treatment. This study highlights the burden associated with parent-focused treatments. Although the study does provide preliminary support for a play-based 
exposure therapy approach, this study used a nonclinical community sample, and children with comorbid anxiety were excluded. Currently, there are no controlled trials of disorder-specific, empirically supported treatments, such as OST, for preschool-aged children with clinical SPs.

Recently, our group developed and piloted a modified OST incorporating play therapy for preschoolers with SP (Farrell et al., in press). Given that highly fearful young children may find concentrated, rapid exposure therapy highly confronting, we integrated play therapy into the commencement of this treatment to (a) assist with rapid rapport building with the therapist and (b) enhance the child's motivation through engaging the child with play. Play therapy, as defined by Landreth (2012), is a child-centered approach whereby the therapist provides selected play materials that facilitate the development of a safe relationship for the child to fully express and explore their feelings, thoughts, experiences, and behaviors. Thus, the essential fundamental element of play therapy is the formation of a safe and trusting therapeutic relationship with the child (see Sweeney \& Landreth, 2011). An initial, controlled, baseline case series $(N=4)$ provided preliminary evidence of the feasibility, acceptability, and effectiveness of this innovative onesession ( 3 hours) therapy, combining child-centered, nondirective play therapy approaches (during Hour 1), with empirically supported OST (during Hours 2 and 3), with 4-year-old preschool children with clinical SPs of dogs (Farrell et al., in press). Results indicated stable phobia symptoms based on diagnostic severity ratings across a 3-week baseline phase. There were significant reductions on clinician-rated, parent-rated, and observed avoidance (Behavioral Avoidance Task) following OST and out to 3-month follow-up. Furthermore, by 3-month follow-up, all children were free of all phobia diagnoses (including non-treated comorbid SPs at pretreatment; no other diagnosis beyond SP were present at baseline). More important, support was found from both parent and child satisfaction of treatment ratings, with $100 \%$ of parents reporting that the treatment had been effective and would recommend it. Children were also favorable, with $100 \%$ saying they found the treatment extremely useful in helping them cope with their fear of dogs. The following presents an illustrative, case description of our play-based, cognitive-behavioral OST for SPs in young children-POP! Pre-schoolers Overcoming Phobias (Farrell et al., in press)—-to provide a detailed description of the technical aspects of the therapeutic approach.

\section{The Case of Emily}

\section{Presenting Problem and Client Description}

Emily (pseudonym) a 4-year-old White female was referred by her mother Linda to participate in a pilot study at the university (which had full human research ethics committee approvals). The study involved an intensive OST augmented with a play-based approach for young children aged 4 years old, diagnosed with an SP of dogs. Emily presented with numerous SPs, which were broadly related to three general fears. These included (a) animal phobias specific to snakes, spiders, dogs, and bees; (b) natural environment phobias specific to thunderstorms, water-particular to swimming pools, and being in the dark; and (c) other phobia, which included an SP of costume characters. An SP of dogs was Emily's primary diagnosis as it held the highest overall clinical severity of all her diagnoses. When confronted by a dog, Emily's subjective distress and physiological arousal were extreme-she would scream, cry, hide behind her mother, and throw tantrum until she was removed from the situation. Emily was fearful of all dogs but particularly smaller dogs (and puppies) who would bounce, jump, bite, and yap-which her mother reported was likely because of the more unpredictable nature of these dogs. This phobia was associated with considerable functional impairment for Emily and impacted the entire family. Emily's leisure and social activities were significantly impaired. For example, she was unable to play in the park if a dog was present; and if a dog entered while she was playing, she would stop her activity, 
become distressed and clingy, and insist that her mother carry her out of the park. If visiting a friend's home, she would refuse to enter the home until the dog was secured in another room and would generally refuse to be in any place if a dog was in the vicinity. These behaviors not only impacted negatively on Emily but also had a negative impact on the family who often were unable to attend social events for fear of causing Emily distress if she was exposed to any of her phobic stimuli, in particular, dogs. On querying Emily about her phobic beliefs (e.g., "What scary things do dogs do to make you feel so afraid?"), Emily's described fears that the dog would jump on her, slobber on her, attack, or bite her.

As a result of Emily's other animal phobias, her playing activities were further curtailed. She was fearful of bees, snakes, and spiders and was constantly in a state of hypervigilance when playing outdoors. Emily would avoid playing outdoors if she thought there was even a small possibility of coming across any of these animals or insects. This often resulted in frequent emotional outbursts in public, which caused stress for the entire family on social outings. The family enjoyed camping but was unable to participate in this activity as often as they would have liked because of the distress this would cause Emily. Emily's elder brother Jack (8 years old) was also impacted, stating that he longed for Emily not to be afraid so that they could enjoy activities outside together.

Emily's natural environment phobia of thunderstorms meant that whenever a thunderstorm was predicted or occurring, Emily would avoid leaving the house. If a thunderstorm occurred on an evening, then she would insist on sleeping with her mother, avoiding being alone. The family owned a swimming pool and as a result of Emily's fear of water, she was unable to participate in family fun in the pool. Although the family would play and swim in the pool, Emily would sit and observe from the side, avoiding entering the water. Emily's fear of costume characters meant that special occasions were often fraught with difficulty for Emily and her family. At Christmas time, whereas Emily's brother would enjoy visiting Santa Clause, Emily was unable to participate. Attending pantomimes or stage shows was not possible for Emily, and walking through shopping malls could be problematic if a costumed character was present. Emily would become so fearful that she would insist on leaving the mall and would avoid looking at the character and would cling to her mother, burying her head and avoiding contact with the costumed character.

As a result of Emily's broad array of SPs, not only was her own life restricted but also the activities the family could participate in together were also limited. Emily's fears were debilitating, and if confronted by her phobic stimuli (or if she perceived she may be), she would shake, cry uncontrollably, cling to an adult, sweat, and have heart palpitations. Despite these difficulties, Emily enjoyed dancing and regular play dates with her kindergarten (pre-formal schooling) friends at her own house.

\section{Background History}

Emily was born in a major capital city in Australia, and she and her elder brother Jack ( 8 years old) lived with their biological parents in a middle-class suburb. Both of Emily's parents worked fulltime. Her mother was employed in a professional health role and her father in a building trade. Emily was described as a shy, sensitive, young child, who met all of her developmental milestones within normal time parameters. She was described as clingy, and, despite having some initial difficulties separating at kindergarten, had settled in well and was achieving well above what was expected for her age. Emily had developed several friendships at kindergarten (part-time play-based learning offered prior to the commencement of formal schooling) and was described as popular with her peer group. Emily had a close relationship with her family; however, her SP symptoms were said to be impacting negatively on her family and restricting their social activities, particularly during the last 6 months. 
Emily was described as having always been a fearful child who would show fear when introduced to novel experiences. Linda identified that Emily's fear of dogs appeared to have onset following an incident when she was a very young child ( 2 years of age). Linda recalled Emily was sitting in her stroller when a dog had approached without warning and attempted to lick her hands. Emily was described as being terrified by this incident. Indeed, Linda reported concern that her own anxious reactions at the time of seeing her daughter so terrified may have exacerbated Emily's fear. Linda herself reported being cautious of dogs prior to this incident. She did not report clinical levels of fear; however, she was certainly uncomfortable around dogs and reported beliefs that dogs were "unpredictable" and "dangerous." She reported worry that she may have made Emily's fears worse by facilitating Emily's ongoing avoidance because she herself was anxious of her daughter being confronted by the phobic stimuli. Linda reported that both she and Emily were completely unable to cope with Emily's level of fear and distress in these circumstances. Being around large dogs was identified as being one of the most difficult situations because Linda experienced both an increase in anxiety because of her own dog-related fears and an intense discomfort in seeing her daughter so fearful. There was no family history of anxiety or phobia on her father's side.

Emily's other phobia presentations (insects, water, storms, costume characters) developed after the onset of her fear of dogs.

\section{Assessment}

Following parental informed consent procedures to participate in a pilot trial (see Farrell et al., in press), several assessments were administered as part of Emily's participation in the study of a play therapy modified OST approach for SP of dogs in preschoolers. Linda was interviewed over the telephone using the Anxiety Disorder Interview Schedule for Children, Parent Version (ADIS-P; Silverman \& Albano, 1996) to identify anxiety, mood, and externalizing disorders based on the Diagnostic and Statistical Manual of Mental Disorders (4th ed., text rev.; DSM-IV-TR) criteria. Although the ADIS-P was designed for use with children 6 years and older, acceptable interrater agreement has been reported for younger children (.77 to .86; Rapee et al., 2005). A full ADIS-P interview was conducted at pretreatment (by the treating clinician), posttreatment, and at 1- and 3-month follow-up (by blind independent raters at all time points except pretreatment). Emily did not meet criteria for any other diagnosis other than SPs at pretreatment.

Ratings of Emily's fear and avoidance were obtained using several assessments. These were taken at pre- and posttreatment, as well as 1 month following treatment, and again at 3 months following treatment. In addition, Emily was assigned to a baseline monitoring period of 3 weeks, whereby ratings were obtained prior to commencing treatment to demonstrate stability of symptoms. The following measures were obtained:

1. ADIS-P (dog phobia module only): including a clinician severity rating (CSR) of the diagnoses, rated on a 9-point Likert scale from 0 (not present) to 8 (extreme severity). A CSR of 4 and above indicates clinical diagnostic severity. At pretreatment, Emily received a CSR of 7 for her SP of dogs.

2. Preschool Anxiety Scale-Revised (PAS-R; Edwards, Rapee, Kennedy, \& Spence, 2010): a parent-based questionnaire for measuring symptoms of DSM-defined anxiety disorders in young children. The PAS-R consists of 28 scored items representing symptoms of social phobia, generalized anxiety, separation anxiety, specific fears, and obsessive-compulsive disorder. Parents are asked to indicate the frequency of which an item is true for their child (e.g., Is afraid of insects and/or spiders?) on a 5-point scale, ranging from 0 (not at all true) to 4 (very often true). Evidence suggests that the PAS-R has sound construct validity and inter-rater reliability (Spence, Rapee, McDonald, \& Ingram, 2001). Emily's mother rated her PAS-R score at pretreatment as 25 (possible score range $0-112$ ). 
3. Parent Ratings of Target Behaviors: Emily's three most troubling symptoms related to her phobia were ascertained based on interviews, and parent ratings of severity were taken. These target behaviors were identified following the ADIS-P interview and discussion with Emily and her mother about her greatest fears. These target behaviors were used to monitor her severity of symptoms and response to treatment over the course of therapy. This involved a rating of Emily's distress on a scale of 0 (not bad at all) to 8 (very, very bad) for each of her target SP symptoms. Emily's target behaviors were defined as (a) being in a park when a dog is present (severity $=8$ ), (b) visiting a friend's home when a dog is present in same room (severity $=6$ ), and (c) approaching and patting a dog on a lead (severity $=6$ ). All measures were taken at each pretreatment assessment, at the OST treatment, and each week following treatment, up to the 1-month follow-up, and then once again at 3-month follow-up.

4. Koala Fear Questionnaire (KFQ: Muris et al., 2003): KFQ is an interview-based, standardized self-report scale for assessing fears and fearfulness in 4 - to 12-year-old children. The scale consists of 31 potentially fear-provoking stimuli and situations that are all illustrated with pictures. For each item, children rate the intensity of their fear using a visual scale from 1 to 3 depicting Koala bears that express varying degrees of fear $(1=$ no fear, $2=$ some fear, $3=$ a lot of fear). Emily's fear on the KFQ was rated at pretreatment as 50 (possible score range 31-93).

Parent ratings were obtained by Linda, whereas the KFQ was administered directly with Emily. The nature of this assessment session, which occurred 1 week prior to the OST sessions, was a play-based session with the aim to build initial rapport and explore the nature of Emily's fears. This session also incorporated a brief psychoeducation session delivered to Linda and Emily together as well as play-based activities. Carefully selected toys were available in the assessment room to facilitate the following: (a) establishing a therapeutic relationship with the child, (b) enabling the child to become familiar with the toys and clinic setting prior to treatment, (c) assisting in a play-based introduction to fear and how the child and therapist might work together to overcome the child's fears, and (d) supporting the therapist in developing story stems which could later be used in treatment to assist the child in beginning to think about their fear of dogs. The structure of the session allowed the child free play to interact with the various play materials, including books, pictures, stuffed animals including dogs, a doll house including animal and dog figures, and coloring in activities of animals and dog scenes. Following administration of the KFQ, the therapist played with the child, allowing the child to direct the play activities while gently discussing (a) the nature of fears (including normalizing that everyone has fears, discussing types of fears the therapist might have, as well as fears that Emily's friends or family members may have) and (b) the approach to overcoming fears through exposure therapy (e.g., with the help of the therapist, the child would be able to face her fear of dogs and overcome this fear by learning how to have fun with dogs).

\section{Case Formulation}

The development and maintenance of Emily's SP can be explained using a cognitive-behavioral model (McLeod, Jensen-Doss, \& Ollendick, 2013).

Predispositions. Emily may have had a biological vulnerability for SP given the maternal history of subclinical anxiety and her own fear of large dogs. In addition, Emily also appears to be temperamentally fearful since toddlerhood. In conjunction with a biological vulnerability and temperamental vulnerability for anxiety, Emily may have also been predisposed to developing anxiety through several learning pathways, in line with Rachman's (1977) fear learning models of anxiety and phobias. For example, Emily may have learned to be fearful of dogs via maternal modeling of anxious behavior as well as Linda's transmission of negative information about dogs_- "dogs are dangerous and unpredictable, so be careful." 
Precipitating Events. The onset of Emily's specific dog phobia was precipitated by an incident when she was a toddler (approximately 2 years of age) where she was approached by a dog while restrained in her stroller. The intense fright of the dog jumping on her, combined with the fact that she was restrained and unable to escape, may have provided a context of conditioned fear learning whereby her experiences of dogs are associated with intense fear and perceived danger. Furthermore, her mother's fear response to this situation provided further learning for Emily that dogs are dangerous, frightening, and should be avoided.

Perpetuating Factors. In an attempt to prevent Emily from becoming distressed, her family facilitates avoidance of a host of situations which might trigger her anxiety. Examples of such situations include requesting friends to remove their dogs from Emily's vicinity, avoiding pantomimes or stage shows, and allowing Emily to observe the family playing in the pool from a distance. Although these measures serve to temporarily reduce Emily's distress in the short term, thus negatively reinforcing her fear and avoidance behaviors, they also serve to prevent her from experiencing new, corrective learning and information about the feared stimuli and her ability to cope in the presence of the stimuli. Thus, Emily's avoidance behaviors serve to maintain her dysfunctional beliefs that dogs are dangerous and that she cannot cope in the presence of dogs, therefore exacerbating her phobic symptoms through a cycle of negative reinforcement of her anxiety symptoms.

Emily's appraisals of threat also likely play a strong role in perpetuating her fear and avoidance because of tendencies of children with phobias to overestimate the probability and severity of danger as well as underestimate their ability to cope when confronted with triggers. Given Emily's age, a formal assessment of her expectancies of danger and coping were not conducted; however, Emily was able to articulate that she feared dogs would definitely harm her and that was far too fearful to be able to face her fear of dogs. Linda's own fear of dogs, as well as her beliefs about Emily's inability to cope, also likely serve to perpetuate fear and avoidance through social learning influences such as modeling, vicarious conditioning, and the transmission of negative verbal information about dogs.

Emily's familial relationships may also play a maintaining role in her phobic symptoms. Linda describes her own anxiety when faced with Emily's fear of dogs, in conjunction with her own dislike of larger dogs, results in a parental rearing style characterized by overinvolvement and overprotection. This rearing style serves to maintain Emily's avoidance through Linda's modification of family life to facilitate Emily's avoidance/escape. Furthermore, her overprotective parenting reinforces Emily's beliefs that the world is a dangerous place and that Emily is unlikely to cope on her own. Together, these early social learning experiences may have served to increase Emily's hypervigilance for danger.

Protective Factors. Emily's family was loving, caring, and supportive and wished for her to be free of her phobic responses. Emily's elder brother was also committed to her recovery as were her parents. Emily was engaged in social activities such as dancing and play dates with her kindergarten friends. During assessment, Emily indicated that she would like to be able to play in the park without being afraid of the presence of dogs, demonstrating some level of motivation to engaging in treatment.

\section{Course of Treatment}

Psychoeducation Session. Following assessment, a comprehensive psychoeducation session in relation to SPs and the treatment of phobias was provided to Emily's parents prior to the OST. This included a theoretical formulation of the acquisition of phobias, a description of the symptoms of phobias, factors known to maintain fear and avoidance, and an overview of the treatment approaches to be implemented. The rationale for the treatment approach, including the intensive nature of the treatment, was also provided. Specifically, the therapist provided an explanation 
that the intensive session would provide a kick start for Emily to overcome her fears, whereby the therapist would help her achieve facing her fears in one concentrated session. However, it was also explained that the gains made would have to be strengthened and generalized via ongoing practice for several week following the OST. Furthermore, Linda received psychoeducation on setting up exposure practices and how to support Emily during exposure practice at home. The use of appropriate reward contingency plans was also discussed to support Emily's ongoing engagement in overcoming her fears.

The Play-Modified One-Session Treatment. POP! Pre-schoolers Overcoming Phobias (Farrell et al., in press) is a modified OST approach (Davis, Ollendick, \& Ost, 2012; Öst \& Ollendick, 2001), whereby play therapy approaches are used for the first hour of the intensive treatment to engage the child at an appropriate developmental level and socialize the child to the goals of treatment (i.e., to face her fears) in a supportive, fun, and nonthreatening way. In recognition of the fact that there are many philosophical differences between different schools of play therapy, Yasenik and Gardner (2004) proposed a dimensional approach to the conceptualization of play therapy as an intervention. The two primary dimensions proposed are those of directiveness and consciousness. The child's play activities and verbalizations are considered to reflect the consciousness dimension, whereas the directiveness refers to the therapists activity in the form of how immersed they are in the child's play (i.e., being nondirective refers to being completely immersed in the child's play activity). During the play therapy intervention, the therapist, guided by the case conceptualization, moved along the continuum of directiveness, beginning with completely child-led play activity to gradually more directive play whereby the therapist engaged the child in dialogue about how the child felt about dogs (using animal and child play figures), what they did when they saw a dog, and how the child might become brave and face her or his fear of dogs with the therapist. With respect to the consciousness dimension, the therapist also moved along the continuum, at times offering timely interpretations to facilitate conscious awareness and insight for the child (e.g., the therapist holding a dog play figure "I think you might like to play with me! I am a friendly puppy_look at my tail wagging, I want to play with you!"), always informed by the case conceptualization, and moving at the pace of the child. Yasenik and Gardner (2004) suggest that this is a useful tool to integrate various models, approaches, and theories to child and play therapy. The gradual integration of directiveness during play (which included low level exposures through the use of dog stimuli) therefore facilitated the shift into much more directive behavioral OST introduced in the second hour. This approach enables the therapist to gradually prepare and scaffold the child within a safe child-centered context to face the more challenging exposure tasks necessary for the treatment of SP.

Hour 1-Child-Centered Play Approaches. During this first hour of therapy, the therapist worked with Emily in a carefully designed play environment where she had access to a range of materials that were specifically chosen based on information obtained during the pretreatment session. The aim of these materials was to facilitate expression for Emily relating to her phobia of dogs and for the therapist to explore Emily's cognitions in relation to her dog phobia. Most play materials were dog-related and included automated dogs, various soft toy dogs, dog figures, dog pictures displayed on the clinic room walls, dog puppets, dog dress-up accessories, a dog board game, and dog art materials, including stickers and coloring in pictures. A doll house, play park with fences, and a small selection of other animals and human figures were included. These were specifically selected to assist both the therapist and the child in exploring feelings and cognitions relating to identified events in the environment whereby Emily often struggled when approached by a dog.

Throughout the play therapy hour, the therapist built Emily's trust in the therapeutic relationship by allowing her to have fun while being exposed to several toy dog interactions. The therapist was guided by the child-centered approach to play therapy (Landreth, 1991) during the play therapy hour. During this time, the therapist reflected Emily's feelings as she engaged in play 
activities, demonstrating to her an interest and desire to understand her. Using the dimensional framework, the therapist began working in a nonintrusive, responsive way. This served to build trust and rapport and allowed Emily to have a sense of control and mastery in her ability to work at her own pace while confronting her phobic stimuli. As the play hour progressed, the therapist took opportunities to move along the continuum, taking a more directive stance in line with a cognitive behavior play therapy approach (Knell \& Moore, 1990).

During this play therapy hour, story stems were used to assist in eliciting Emily's emotional responses and cognitions to the phobic stimulus (Bretherton, Ridgeway, \& Cassidy, 1990), and play sequences were used to model how to bravely behave when approached by a dog. Specific play sequences were predetermined by the therapist following information gathered during the pretreatment session. The therapist directed the play only when deemed necessary to elicit Emily's emotional response, assist with the development of positive coping statements, or model appropriate dog behavior. An example of a story stem was where Emily had identified being fearful of dogs in the park. The therapist directed her play to include children playing in the park. A dog (directed by the therapist) approached and jumped at the child figure (Emily is directing the child figure), and the therapist asked Emily, "I wonder what happens next." Emily indicated to run away. The therapist asked Emily how scared the little girl (doll figure) was, using the fear scale the therapist had introduced during the first assessment/education session (visual subjective units of distress scale 0-10), and Emily indicated moderate fear. The therapist then modeled with another child figure remaining calm and approaching the dog to see if it was friendly. The therapist, using the other child play figure, gradually approached the dogs and said, "You look like you are a friendly dog; you are wagging your tail. I would like to pat you." The play sequence was repeated, and Emily was encouraged to take the part of approaching the dog. During the sequence, positive coping statements such as "I can be brave around dogs" and "this dog seems friendly, I can see his tail is wagging, he must want to play" were encouraged. Thus, the play therapy hour did include low-level exposures, which through play were tolerable to Emily.

Furthermore, play sequences involved helping Emily learn new skills (e.g., learning how to stand like a tree when a dog approached), which were to be later practiced in the exposure and homework tasks. This was achieved through the development of play sequences involving the automated dog that would bark and move in unpredictable ways. The therapist began by initiating a play sequence of walking in the park while Emily controlled the dog and the therapist modelled how to stand like a tree. Roles were then reversed, with Emily practicing standing like a tree while the therapist assessed her expectancies about what might happen. The purpose was to work toward Emily developing less threatening appraisals of the scenarios as well as more positive coping statements.

Emily was encouraged to interact with a wide range of dog-related stimuli during this hour to facilitate rapid yet very small exposure therapy steps. For example, Emily was encouraged to interact with various dog pictures on the wall, some of which were small, friendly-looking dogs and others that were large, fierce-looking dogs. A playful approach was adopted to see who could make the fierce dogs look the funniest by drawing disguises (i.e., glasses and beards) on their faces and giving each dog a cute or funny name. This facilitated Emily engaging her attention to the details of the dogs that previously she appraised as very threatening. Throughout this process, the therapist would continue to ask questions regarding what she noticed about the dogs as well as how she was feeling. Her fear-based cognitions were challenged as she continued to play and change the look of the dogs, leading to a sense of mastery and control through the play experience.

At the end of the first hour, Emily was eager to show her mother what she had achieved in facing her fears. Emily was positively reinforced by her mother for her new learning. At this stage, Emily was already enthusiastic about meeting her first real dog in the exposure (POP!) room. During the play hour, Emily had become attached to a soft toy dog and requested that she be 
allowed to take it into the POP! room with her to meet the real dog. Given that the toy appeared to offer a sense of safety and security for Emily, it was used as a tool for facilitating Emily's exposure to the real dog.

Hours 2 and 3-One-Session Treatment. In line with Öst and Ollendick (2001) and later Zlomke and Davis (2008) and Davis et al. (2012), the second and third hours of the intensive session involved more therapist-directed, graduated, in vivo exposure embedded within a series of behavioral tests that Emily was encouraged to attempt to obtain new information about dogs and her ability to cope with them. Cognitive challenges were incorporated into the exposure process, whereby the therapist questioned Emily as to what she thought would happen during the exposure task prior to commencing the actual exposure (e.g., "What do you think will happen if you pat the dog on its head?"). Following the exposure, the therapist would ask Emily what actually happened and whether her belief came true (e.g., "You are patting the dog on its head and has it bitten you?"). This process assists the child to obtain new information about the phobic stimuli, learn how they coped in the presence of the stimuli, and correct catastrophic cognitions maintaining fear and avoidance.

Participant modeling is another key technique that is used to break down difficult steps in the child's exposure hierarchy into more manageable tasks (Davis et al., 2012). It involves a model (usually the therapist) demonstrating a behavior and then incorporating the child into the modeled behavior. For example, after demonstrating to Emily how to pat a dog, the therapist asked her to place her hand on top of the therapist's hand to have them pat the dog together until Emily's fear habituated to the point that the therapist could then allow Emily to pat the dog on her own. Thus, physical contact was gradually phased out with only verbal instruction provided instead. During OST, Emily was also provided with ongoing psychoeducation and skills training. The therapist highlighted positive information about dogs to Emily and educated her about how to successfully interact with the dog (e.g., approach a dog if its tail is wagging).

Emily was encouraged to interact with two different dogs during the 2 hours, one for each hour of the remaining OST session. The dogs had different activity levels and were different sizes, breeds, and colors. Emily was encouraged to engage in a range of different tasks with each dog including standing like a tree while the dog approached her on a lead, approaching and patting the dog, offering the dog treats, and walking the dog on the lead. Each task was repeated multiple times until Emily's anxiety had reduced by at least $50 \%$ by the end of each task as rated by a cartoon-illustrated feelings thermometer (subjective units of distress scale). The therapist provided praise and small rewards (dog stickers, dog lollies) to Emily throughout the session to reinforce her approach behaviors. At the end of the session, Emily's progress was reviewed with her mother, and together homework tasks of exposure to various dogs in multiple settings were set. The play-based hour and exposure session was conducted at Emily's pace and was adjusted based on her responses to the various exposure tasks.

\section{Parental Involvement in Treatment}

Linda was actively involved in all aspects of the treatment, including the pretreatment psychoeducation session, following the end of Emily's intensive session, and during the brief (20-min) weekly telephone support which occurred over 3 weeks following OST. These telephone calls assist in a maintenance phase of treatment, whereby the therapist provides brief calls with the aim to encourage ongoing practice and to brainstorm any problems that may arise with ongoing exposure practice at home. At the end of each hour of OST, Emily was encouraged to share the progress she had made with her parents by demonstrating behaviorally what she had achieved in her interactions with the play materials/dogs. At both the midway point and end of the OST, Linda had the opportunity to observe the therapist model appropriate responses to Emily's 


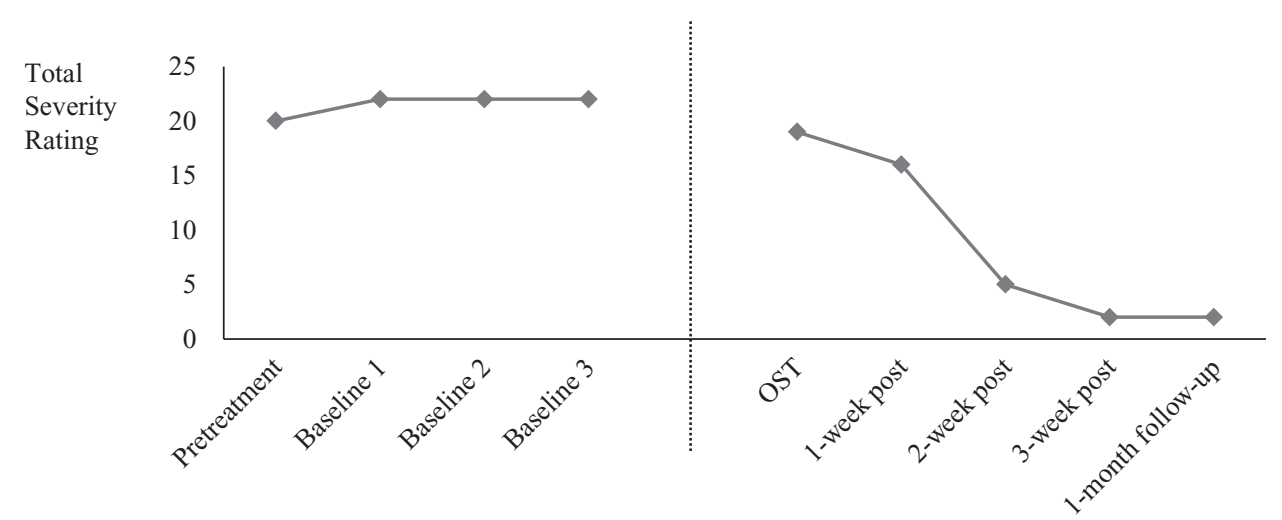

Figure 1. Parental reports of Emily's target behavior-patting a dog while on a lead. OST = onesession treatment.

phobic behavior and ways to encourage and establish exposure practice to challenge Emily's phobic beliefs. At the conclusion of the intensive session and at 1-month follow-up, Emily and Linda briefly reviewed progress that had been made during the session and across weekly monitoring. They were also reminded of the importance of scheduling exposure time at home to continue their progress.

\section{Outcome and Prognosis}

Following a systematic assessment that occurred 1 month after treatment (during which Emily had continued with exposure practice at home), Emily no longer met criteria for any SP based on the ADIS-P interview. Emily's mother described encouraging Emily to face her other SP fears following the OST session, which Emily was willing and able to do following OST. Thus, it seems the OST was successful in providing Emily the skills and mastery to approach her other fears successfully and overcome these SPs. Her CSR score was 0 for her SP of dogs, indicating no evidence of SP symptoms, and this was maintained at a 3-month follow-up. Emily's three most distressing phobic symptoms were also rated throughout the treatment process with a reduction in distress across all symptoms. At posttreatment, Emily rated 0 (out of 8 ) for two of her phobic symptoms and 2 (out of 8 ) for the third symptom (see Figure 1 for her target behavior severity ratings). Emily reported a reduction in her overall fear, with a reduction of 16 points on the KFQ, whereas her mother reported a reduction of 24 points on the PAS-R indicating Emily's overall levels of anxiety and fear were within normal range at posttreatment and follow-up.

\section{Summary and Key Practice Points}

This case describes a concentrated, time-limited approach to CBT for preschool-aged children with SP. Specifically, an OST augmented with play therapy was delivered to a 4-year-old girl with a severe SP of dogs. The outcomes of this case were very favorable, with a complete remission of her SP at 1-month follow-up, which was maintained at 3-month following this treatment, and considerable reductions on measures of fear and anxiety. More important, this case study speaks to the feasibility of delivering an intensive, one-session exposure therapy treatment for 
a very young child who was severely phobic at pretreatment. The outcomes of this case study provide promise for more efficient models of child-focused treatment delivery, with outcomes demonstrating rapid improvements following a single-session exposure-based approach. Future research, including RCTs and dismantling studies, are necessary to establish the efficacy of the approach and the relative efficacy of the play therapy components and the more conventional behavioral approaches of OST. Furthermore, the inclusion of measures such as child motivation, as well as alliance/rapport in future research, would also be useful to inform the mechanisms by which play therapy exerts its effects on outcome.

Although most therapists endorse a CBT orientation and use CBT techniques, therapistassisted in vivo exposure therapy is not routinely delivered in routine clinical practice for childhood anxiety disorders (Whiteside, Deacon, Benito, \& Stewart, 2016). Although most therapists endorse a CBT orientation and use CBT techniques, exposure therapy is rarely endorsed in routine clinical practice for childhood anxiety disorders (Whiteside et al., 2016). There are numerous reasons for this, including therapist preferences as well as parent and/or child reluctance to engage in exposure. This case study demonstrates that using a dimensional approach, whereby the therapist engages the child using nondirective play therapy during assessment, psychoeducation, and the first hour of therapy, young children may indeed be willing to progress quite rapidly into more therapist-directed, cognitive-behavioral approaches including in vivo exposure therapy within a single session. This approach moves beyond "child-friendly" CBT to highlight the arguably essential step of using child-centered, nondirective play to facilitate a trusting relationship with the child, whereby the child can develop a sense of mastery in fighting his or her fears in a nonthreatening, supported way facilitated by play. This step then allows the child to be led by the therapist into a gradually, more directive cognitive-behavioral therapy. Beyond feasibility, this case study also provides evidence that the treatment was also highly acceptable to Emily and Linda, both of whom reported that Emily liked the approach and that they would highly recommend the approach to others.

In conclusion, we highlight several important clinical considerations for adapting CBT for young children with SPs:

1. To engage the very young child, it is essential that the therapist be focused on building alliance and rapport with the child and parents from the very initial contact with the family. The therapist should be highly empathic, show unconditional positive regard and genuineness to establish rapport, and create a safe, trusting relationship to enable the child to face his or her specific dog fears later in treatment.

2. The assessment phase and play therapy phase should occur in a room that is set up for play therapy. Ensure a wide array of play materials that relate to the child's phobia. Within the assessment phase, the child is encouraged to play with the toys in a nondirective way while the therapist assesses the child's willingness to explore various materials and his or her interests. This allows the therapist to plan for individual story stems and play sequences in the first hour of the OST therapy session.

3. The child is moved into another room for the final 2 hours of OST where he or she is encouraged to approach the stimuli (e.g., the dogs) in a gradual, therapist-supported way. Positive reinforcement, participant modeling, and exposure games are used to facilitate approach behavior. The therapist assists the child to develop more positive appraisals of the stimuli as well as enhance coping expectancies through the use of behavioral experiments.

4. The intensive approach should be viewed as a kick start to therapy; as such, therapists are encouraged to make plans with clients for regular, albeit brief, check-ins with the family to ensure compliance with exposure practice after the concentrated treatment. Furthermore, booster sessions, spaced monthly, then every 3 months and every 6 months, may facilitate generalization of gains and prevent relapse. 


\section{REFERENCES}

American Psychiatric Association. (2013). Diagnostic and statistical manual of mental disorders (5th ed.). Arlington, VA: Author.

Bittner, A., Egger, H. L., Erkanli, A., Costello, E., Foley, D. L., \& Angold, A. (2007). What do childhood anxiety disorders predict? Journal of Child Psychology and Psychiatry, 48(12), 1174-1183.

Bretherton, I., Ridgeway, D., \& Cassidy, J. (1990). Assessing internal working models of the attachment relationship. In M. T. Greenberg, D. Cicchetti, \& E. M. Cummings (Eds.), Attachment in the preschool years: Theory, research, and intervention (pp. 273-308). Chicago, IL: The University of Chicago Press.

Bufferd, S. J., Dougherty, L. R., Carlson, G. A., Rose, S., \& Klein, D. N. (2012). Psychiatric disorders in preschoolers: Continuity from ages 3 to 6. American Journal of Psychiatry, 169(11), 1157-1164.

Cartwright-Hatton, S., Reynolds, S., \& Wilson, C. (2011). Adult models of anxiety and their application to children and adolescents. In W. Silverman \& A. Field (Eds.), Anxiety disorders in children and adolescents (2nd ed., pp. 129-158). Cambridge, United Kingdom: Cambridge University Press.

Cole, D. A., Peeke, L. G., Martin, J. M., Truglio, R., \& Seroczynski, A. D. (1998). A longitudinal look at the relation between depression and anxiety in children and adolescents. Journal of Consulting and Clinical Psychology, 66(3), 451-460.

Costello, E. J., Egger, H. L., \& Angold, A. (2005). The developmental epidemiology of anxiety disorders: Phenomenology, prevalence, and comorbidity. Child and Adolescent Psychiatric Clinics of North America, 14(4), 631-648.

Davis, T. E., \& Ollendick, T. H. (2005). Empirically supported treatments for specific phobia in children: Do efficacious treatments address the components of a phobic response? Clinical Psychology: Science and Practice, 12(2), 144-160.

Davis, T. E., Ollendick, T. H., \& Öst, L. G. (2012). Intensive one-session treatment of specific phobias. New York, NY: Springer.

Donovan, C. L., \& March, S. (2014). Online CBT for preschool anxiety: A randomized controlled trial. Behaviour Research and Therapy, 58, 24-35.

Edwards, S. L., Rapee, R. M., Kennedy, S. J., \& Spence, S. H. (2010). The assessment of anxiety symptoms in preschool-aged children: The revised Preschool Anxiety Scale. Journal of Clinical Child \& Adolescent Psychology, 39(3), 400-409.

Egger, H. L., \& Angold, A. (2006). Common emotional and behavioral disorders in preschool children: Presentation, nosology, and epidemiology. Journal of Child Psychology and Psychiatry, 47(3-4), 313-337.

Farrell, L. J., Kershaw, H., \& Ollendick, T. H. (in press). One-session treatment for preschoolers with specific phobias: A controlled multiple baseline design. Cognitive and Behavioural Practice.

Flatt, N., \& King, N. (2010). Brief psycho-social interventions in the treatment of specific childhood phobias: A controlled trial and a 1-year follow-up. Behaviour Change, 27(3), 130-153.

Fox, N.A., \& Pine, D. S. (2012). Temperament and the emergence of anxiety disorders. Journal of the American Academy of Child and Adolescent Psychiatry, 51(2), 125-128.

Freeman, J. B., Garcia, A. M., Coyne, L., Ale, C., Przeworski, A., Himle, M., . . . Leonard, H. L. (2008). Early childhood OCD: Preliminary findings from a family-based cognitive-behavioral approach. Journal of the American Academy of Child \& Adolescent Psychiatry, 47(5), 593-602.

Gregory, A. M., Caspi, A., Moffitt, T. E., Koenen, K., Eley, T. C., \& Poulton, R. (2007). Juvenile mental health histories of adults with anxiety disorders. American Journal of Psychiatry, 164(2), 301-308.

Hirshfeld-Becker, D. R., Masek, B., Henin, A., Blakely, L. R., Pollock-Wurman, R. A., McQuade, J., . . . Biederman, J. (2010). Cognitive behavioral therapy for 4- to 7-year-old children with anxiety disorders: A randomized clinical trial. Journal of Consulting and Clinical Psychology, 78(4), 498-510.

Hirshfeld-Becker, D. R., Micco, J. A., Mazursky, H., Bruett, L., \& Henin, A. (2011). Applying cognitivebehavioural therapy for anxiety to the younger child. Child and Adolescent Psychiatric Clinics of North America, 20, 349-368. 
Kendall, P. C., Safford, S., Flannery-Schroeder, E., \& Webb, A. (2004). Child anxiety treatment: Outcomes in adolescence and impact on substance use and depression at 7.4-year follow-up. Journal of Consulting and Clinical Psychology, 72(2), 276-287.

Kennedy, S. H., Milev, R., Giacobbe, P., Ramasubbu, R., Lam, R. W., Parikh, S. V., . . Ravindran, A. V. (2009). Canadian Network for Mood and Anxiety Treatments (CANMAT) clinical guidelines for the management of major depressive disorder in adults. IV. Neurostimulation therapies. Journal of Affective Disorders, 117, S44-S53.

Knell, S. M., \& Moore, D. J. (1990). Cognitive-behavioural play therapy in the treatment of encopresis. Journal of Clinical Child Psychology, 19(1), 55-60.

Landreth, G. (1991). Play therapy: The art of the relationship (2nd ed.). Denton, TX. Brunner-Routledge.

Landreth, G. L. (2012). Play therapy: The art of the relationship. London, United Kingdom: Routledge.

Leutgeb, V., Schäfer, A., Köchel, A., \& Schienle, A. (2012). Exposure therapy leads to enhanced late frontal positivity in 8- to 13-year-old spider phobic girls. Biological Psychology, 90(1), 97-104.

Leutgeb, V., \& Schienle, A. (2012). Changes in facial electromyographic activity in spider-phobic girls after psychotherapy. Journal of Psychiatric Research, 46(6), 805-810.

May, A. C., Rudy, B. M., Davis, T. E., \& Matson, J. L. (2013). Evidence-based behavioral treatment of dog phobia with young children two case examples. Behavior Modification, 37(1), 143-160.

McLeod, B., Jensen-Doss, A., \& Ollendick, T. (2013). Diagnostic and behavioral assessment in children and adolescents: A clinical guide. New York, NY: Guilford Press.

Merikangas, K. R., He, J. P., Burstein, M., Swendsen, J., Avenevoli, S., Case, B., .. Olfson, M. (2011). Service utilization for lifetime mental disorders in US adolescents: Results of the National Comorbidity SurveyAdolescent Supplement (NCS-A). Journal of the American Academy of Child \& Adolescent Psychiatry, 50(1), 32-45.

Muris, P., Meesters, C., Mayer, B., Bogie, N., Luijten, M., Geebelen, E., . . Smit, C. (2003). The Koala Fear Questionnaire: A standardized self-report scale for assessing fears and fearfulness in pre-school and primary school children. Behaviour Research and Therapy, 41(5), 597-617.

Muris, P., Merckelbach, H., \& Collaris, R. (1997). Common childhood fears and their origins. Behaviour Research and Therapy, 35(10), 929-937.

Muris, P., Merckelbach, H., Holdrinet, I., \& Sijsenaar, M. (1998). Treating phobic children: Effects of EMDR versus exposure. Journal of Consulting and Clinical Psychology, 66(1), 193-198.

Oh, E., Mathers, M., Hiscock, H., Wake, M., \& Bayer, J. (2015). Professional help seeking for young children with mental health problems. Australian Journal of Psychology, 67, 187-195.

Ollendick, T. H., Halldorsdottir, T., Fraire, M. G., Austin, K. E., Noguchi, R. J., Lewis, K. M., .. . Whitmore, M. J. (2015). Specific phobias in youth: A randomized controlled trial comparing one-session treatment to a parent-augmented one-session treatment. Behaviour Therapy, 46, 141-155.

Ollendick, T. H., \& Muris, P. (2015). The scientific legacy of Little Hans and Little Albert: Future directions for research on specific phobias in youth. Journal of Clinical Child and Adolescent Psychology, 44(4), 689-706.

Ollendick, T. H., Öst, L. G., Reuterskiöld, L., Costa, N., Cederlund, R., Sirbu, C., . . Jarrett, M. A. (2009). One-session treatment of specific phobias in youth: A randomized clinical trial in the United States and Sweden. Journal of Consulting and Clinical Psychology, 77(3), 504-516.

Öst, L. G. (1989). One-session treatment for specific phobias. Behaviour Research and Therapy, 27(1), 1-7.

Öst, L. G., \& Ollendick, T. H. (2001). Manual for the one-session treatment of specific phobias in children and adolescents. Unpublished manual.

Öst, L. G., Svensson, L., Hellström, K., \& Lindwall, R. (2001). One-session treatment of specific phobias in youths: A randomized clinical trial. Journal of Consulting and Clinical Psychology, 69(5), 814-824.

Rachman, S. (1977). The conditioning theory of fear-acquisition: A critical examination. Behaviour Research and Therapy, 15(5), 375-387.

Rapee, R. M., Kennedy, S. J., Ingram, M., Edwards, S. L., \& Sweeney, L. (2005). Prevention and early intervention of anxiety disorders in inhibited preschool children. Journal of Consulting and Clinical Psychology, $73(3), 488-497$. 
Rapee, R. M. (2013). The preventative effects of a brief, early intervention for preschool-aged children at risk for internalising: Follow-up into middle adolescence. Journal of Child Psychology and Psychiatry, 54(7), 780-788.

Santacruz, I., Méndez, F. J., \& Sánchez-Meca, J. (2006). Play therapy applied by parents for children with darkness phobia: Comparison of two programmes. Child \& Family Behavior Therapy, 28(1), 19-35.

Silverman, W. K., \& Albano, A. M. (1996). Anxiety disorders interview schedule for DSM-IV: Child interview schedule. New York, NY: Graywind.

Spence, S. H., Rapee, R., McDonald, C., \& Ingram, M. (2001). The structure of anxiety symptoms among pre-schoolers. Behaviour Research and Therapy, 39(11), 1293-1316.

Sweeney, D. S., \& Landreth, G. L. (2011). Child-centered play therapy. In C. Schaefer (Ed.), Foundations of play therapy (pp. 129-152). Hoboken, NJ: Wiley.

van der Sluis, C. M., van der Bruggen, C. O., Brechman-Toussaint, M. L., Thissen, M. A., \& Bögels, S. M. (2012). Parent-directed cognitive behavioral therapy for young anxious children: A pilot study. Behavior Therapy, 43(3), 583-592.

Waters, A. M., Farrell, L. J., Zimmer-Gembeck, M. J., Milliner, E., Tiralongo, E., Donovan, C. L., . . . Ollendick, T. H. (2014). Augmenting one-session treatment of children's specific phobias with attention training to positive stimuli. Behaviour Research and Therapy, 62, 107-119.

Waters, A. M., Ford, L. A., Wharton, T. A., \& Cobham, V. E. (2009). Cognitive-behavioural therapy for young children with anxiety disorders: Comparison of a child + parent condition versus a parent only condition. Behaviour Research and Therapy, 47(8), 654-662.

Whiteside, S. P., Deacon, B. J., Benito, K., \& Stewart, E. (2016). Factors associated with practitioners' use of exposure therapy for childhood anxiety disorders. Journal of Anxiety Disorders, 40, 29-36.

Yasenik, L., \& Gardner, K. (2004). Play therapy dimensions model: A decision-making guide for therapists. Calgary, Canada: The Rocky Mountain Play Therapy Institute.

Zlomke, K., \& Davis, T. E. III. (2008). One-session treatment of specific phobias: A detailed description and review of treatment efficacy. Behavior Therapy, 39, 207-223.

Correspondence regarding this article should be directed to Lara J. Farrell, PhD, School of Applied Psychology and Menzies Health Institute, Griffith University, Gold Coast Campus, Southport, Queensland, Australia 4222.

E-mail: l.farrell@griffith.edu.au 